TITLE:

\title{
A descriptive analysis of end-of-life discussions for high-grade glioma patients(Dissertation_全文)
}

\section{AUTHOR(S):}

Chikada, Ai

\section{CITATION:}

Chikada, Ai. A descriptive analysis of end-of-life discussions for high-grade glioma patients. 京都大学, 2021, 博士 (人間健康科学)

ISSUE DATE:

2021-05-24

URL:

https://doi.org/10.14989/doctor.k23385

RIGHT:

許諾条件により本文は2022-02-04に公開 


\title{
A descriptive analysis of end-of-life discussions for high-grade glioma patients
}

\section{Ai Chikada, Sayaka Takenouchi, Yoshiki Arakawa, and Kazuko Nin ${ }^{\circledR}$}

Department of Human Health Sciences, Graduate School of Medicine, Kyoto University, Kyoto, Japan (A.C., S.T., K.N.); Department of Neurosurgery, Graduate School of Medicine, Kyoto University, Kyoto, Japan (Y.A.)

Corresponding Author: Kazuko Nin, PhD, Department of Human Health Sciences, Graduate School of Medicine, Kyoto University, 53 Kawahara-cho, Shogoin, Sakyo-ku, Kyoto 606-8507, Japan (nin@ kuhp.kyoto-u.ac.jp).

\begin{abstract}
Background. End-of-life discussions (EOLDs) in patients with high-grade glioma (HGG) have not been well described. Therefore, this study examined the appropriateness of timing and the extent of patient involvement in EOLDs and their impact on HGG patients.

Methods. A cross-sectional survey was conducted among 105 bereaved families of HGG patients at a university hospital in Japan between July and August 2019. Fisher's exact test and the Wilcoxon rank-sum test were used to assess the association between patient participation in EOLDs and their outcomes.

Results. In total, 77 questionnaires were returned (response rate 73\%), of which 20 respondents replied with refusal documents. Overall, 31/57 (54\%) participated in EOLDs at least once in acute hospital settings, and a significant difference was observed between participating and nonparticipating groups in communicating the patient's wishes for EOL care to the family $(48 \%$ vs $8 \%, P=.001)$. Moreover, $>80 \%$ of respondents indicated that the initiation of EOLDs during the early diagnosis period with patients and families was appropriate. Most EOLDs were provided by neurosurgeons (96\%), and other health care providers rarely participated. Additionally, patient goals and priorities were discussed in only $28 \%$ of the EOLDs. Patient participation in EOLDs was not associated with the quality of EOL care and a good death.

Conclusions. Although participation in EOLDs is relatively challenging for HGG patients, this study showed that participation in EOLDs may enable patients to express their wishes regarding EOL care. It is important to initiate EOLDs early on through an interdisciplinary team approach while respecting patient goals and priorities.
\end{abstract}

\section{Keywords}

advance care planning | bereavement | end-of-life care | end-of-life discussion | malignant glioma

High-grade gliomas (HGGs) are the most frequently occurring primary malignant brain tumors. ${ }^{1}$ Patients with HGG differ from patients with other cancers ${ }^{2-4}$ because they have a unique illness trajectory whose onset and disease recurrence are often sudden and catastrophic, ${ }^{4}$ and the prognosis is poor despite advanced treatments, such as surgery, radiotherapy, and chemotherapy. ${ }^{2,5,6}$ Moreover, patients with HGG often experience varied physical, cognitive, and psychosocial declines early on in the illness trajectory. 4,5,7 Cognitive decline often causes loss of decision-making capacity, even in the early stages of the disease. ${ }^{1,2,8-11}$
Palliative care $(P C)$ is a proactive and systematic approach to relieve suffering in many dimensions, including physical, psychosocial, and spiritual, and improve the health-related quality of life (HROOL) of patients with life-threatening illnesses, such as $\mathrm{HGG}$, and their families during the entire course of a patient's illness. ${ }^{3,12-15}$ Advance care planning (ACP) is a process aimed at the timely involvement of patients and their relatives in decision-making on future care. ${ }^{16}$ The recommended implementation of early PC includes the ACP process, eg, clarification of treatment goals and assistance with medical decision-making. ${ }^{15,16}$ Walbert et al. suggested that early 
PC interventions through a structured ACP may be helpful for symptom control and quality of life improvement in patients with HGG. ${ }^{13}$

End-of-life discussions (EOLDs) are a core component of ACP. In EOLDs, patients, their families, and health care providers (HCPs) discuss patient prognosis, preferences, and priorities (eg, life-prolonging- and/or palliative treatments and place of care and death), while respecting and reflecting patient values and life goals. ${ }^{17-19}$ Previous studies have suggested that early initiation of EOLDs in the disease course of patients with advanced cancer allows patients and their families to process information and derive maximal benefit from palliative or hospice services. ${ }^{1,20-23}$ Furthermore, EOLDs may enable patients to experience a better quality of end-of-life (EOL) care and death by receiving care consistent with their preferences; similarly, it may help bereaved family members handle depression and complicated grief better. ${ }^{1,19,21,22,24-26}$ Further, in recent decades, there has been an increasing emphasis on patient autonomy, and many patients wish to be involved in treatment-related decision-making. ${ }^{27}$

Since HGG is incurable and cognitive function declines rapidly as the disease progresses, many HGG patients would eventually be unable to participate in EOLDs. ${ }^{2} \mathrm{~A}$ retrospective small chart review study reported that EOLDs occurred relatively late and infrequently reflected patient goals or priorities. ${ }^{19}$ Thus, several previous studies have recommended proactive and early EOLDs that may lead to a dignified death by respecting the autonomy of patients with HGG. $1,2,6,8,9,13,28,29$ Although the European Association for Neuro-Oncology published guidelines on PC for adult glioma patients in 2017 and mentioned $\mathrm{ACP}^{29}$ the optimal timing and clinical intervention for EOLDs are unclear, based on the currently available literature, in patients with HGG. Despite the well-known importance of EOLDs in patients with $\mathrm{HGG}$, there is limited information on the patterns and effects of EOLDs in patients with HGG. ${ }^{2}$

Therefore, this study examined the appropriateness of timing and the extent of patient involvement in EOLDs and their impact on HGG patients based on a questionnaire that was administered to bereaved families of patients with HGG.

\section{Materials and Methods}

\section{Participants}

First, we identified deceased patients from electronic medical records of patients diagnosed with HGG and hospitalized in the Department of Neurosurgery, Kyoto University Hospital, from October 2007 to February 2019. Kyoto University Hospital is a large tertiary university hospital, accredited for expertise in HGG in Japan. Subsequently, we identified eligible deceased patients who were reported to have died from HGG and/or its treatment complications, had a history of hospitalization at Kyoto University Hospital for more than 3 days until death after HGG recurrence, and were more than 20 years old at the time of death. The study subjects were identified from the bereaved families of the previously identified eligible deceased patients. Each of the bereaved families had indicated a key person (first and emergency contact) in the medical record in case informed consent was required or an emergency occurred, and they were required to be at least 20 years old. The exclusion criteria for bereaved families were as follows: serious psychological distress determined by the physician according to evaluation during patient care before the patients' death, no identifiable bereaved family member, and the inability of the bereaved family to complete the questionnaire because of dementia or problems with vision. This research was approved after an ethics review by the Kyoto University Graduate School and Faculty of Medicine, Kyoto University Hospital Ethics Committee (R1941), and all participants provided informed consent.

\section{Design}

In July 2019, we conducted a cross-sectional survey by mailing a cover letter; an anonymous and self-administered questionnaire regarding patients and bereaved families' characteristics, experiences of EOLDs, and EOLD outcomes; and refusal documentation to 115 bereaved family members. Refusal documentation allowed the subjects to refuse to answer the questionnaire, and we requested for the reason for their refusal. Participants were required to return the questionnaire or refusal documentation within 2 weeks. A second request was sent 2 weeks after the initial survey. In the returned questionnaire, we contacted and confirmed all (30 participants) with missing data and/ or discrepancies or inconsistencies compared to the electronic medical record information. Subsequently, we included these questionnaires in the analysis.

\section{Measurements}

Our questionnaire explored the current practice of EOLDs among patients with HGG. Patients with HGG in Japan are often treated in acute hospital settings equipped with specialized treatment facilities, such as university hospitals until antitumor treatment is no longer possible. EOLDs were defined as the discussions between patients with HGG and/or their families or loved ones and HCPs about their preferences for EOL treatment and care while considering patients' wishes and priorities in acute hospital settings. ${ }^{28,30-33}$ The questionnaire was developed in three steps. First, researchers drafted the questionnaire based on a literature review ${ }^{28,32,33}$ and clinical experience in HGG patient care. Second, we received feedback from one neuro-oncologist, one PC specialist, two nurses well experienced in neuro-oncology, four nursing researchers, five ordinary people of various generations who were not relevant to this study, and one bereaved family (mother) member of a deceased patient with HGG. Finally, we revised the draft accordingly and confirmed the face validity of the questionnaire.

We surveyed a proportion of the participants in EOLDs. Further, based on a previous study ${ }^{34}$ and clinical practice experiences, we determined phases in the illness trajectory as follows: $A$, from diagnosis to the end of initial treatment, including surgery and chemoradiation; $B$, during 
maintenance adjuvant chemotherapy; $\mathrm{C} 1$, recurrence and new treatment including second and third, surgery, chemotherapy, and radiation therapy; $\mathrm{C} 2$, the timing of the final tumor-directed treatment; and $D$, the timing of hospice $\mathrm{PC}$ and/or life-prolonging treatment during the EOL phase. Subsequently, we asked whether deceased patients and/or their families had participated in EOLDs during each illness phase. If affirmed, participants were asked the following questions: whether the deceased patients had decision-making capacity when they participated in EOLDs; whether the following topics were discussed: patient goals and priorities, treatment goals and choices, life-prolonging treatment, use of PC services for the EOL phase, preferred place of EOL care, and preferred place of death; and which HCPs had participated (neurosurgeon, nurse in the neurosurgery department, nurse in the community health care coordination unit, outpatient nurse, physician in the PC team, nurse in the PC team, radiologist, and medical social worker, among others). Similarly, we asked about their perception of the timing of the EOLD in which they participated (too early, appropriate, a little bit late, too late).

We used the Care Evaluation Scale version 2.0 (CES 2.0) short version. ${ }^{35}$ The CES 2.0 is a validated and reliable scale to measure the quality of the structure and the processes of EOL care from the perspective of bereaved families within a month before death at the place of the patients' death. The short version of CES 2.0 consists of 10 domains, and each item is evaluated using a 6-point Likert scale. Participants were also asked to select "7: Non-applicable" if none of the other scores was applicable to the patient. The scores were converted to a 0-100 scale, with higher scores indicating good structure or process of care. CES 2.0 is a modified version of the Care Evaluation Scale version 1.0 (CES 1.0), which has been validated outside Japan. ${ }^{36}$ It has been suggested that CES 2.0 eliminates misresponses associated with CES 1.0, while maintaining good reliability and validity. ${ }^{35}$

Similarly, we used the Good Death Inventory (GDI) short version. ${ }^{37}$ The $\mathrm{GDI}$ is a validated and reliable tool for measuring the quality of death from the perspective of the bereaved family. The GDI consists of 18 domains, including 10 core and 8 optional domains. The 10 core domains evaluate attributes that most Japanese consistently rated as important, whereas the 8 optional domains evaluate attributes that are not as consistently rated as important as the 10 core domains. In this study, we used the short version of the GDI 18 domains, which consists of 18 representative items from each of the $18 \mathrm{GDI}$ domains. Each item was evaluated on a 7-point Likert scale, with a total possible score between 18 and 126 . Higher scores indicate better death quality. The GDI has been validated outside Japan. ${ }^{38}$ In this study, we evaluated the GDI of phase D for patients receiving EOL care in the illness trajectory.

\section{Statistical Analysis}

We conducted descriptive statistics to estimate the frequencies and means for all variables. Similarly, we stratified according to the presence or absence of EOLDs and used Fisher's exact test and the Wilcoxon rank-sum test to compare the association between patient participation in EOLDs and EOLD outcome measures, including the occurrence of conversation and/or documentation of patient wishes for EOLD care, place of death concordant with patients' wish, quality of EOL care, and quality of death. We used JMP ${ }^{\circledR}$ Pro 14 (SAS Institute Inc., Cary, NC, USA) for statistical analyses. We reported two-sided $P$ values and considered values of $P<.05$ to be statistically significant.

\section{Results}

In total, $344 \mathrm{HGG}$ cases were diagnosed and registered at Kyoto University Hospital in Japan between October 1, 2007 and February 28, 2019. Of these, 155 were excluded as patients were alive or their survival was unknown. Thus, we identified 189 decedents as potential participants. Of these, 74 were excluded for not meeting the inclusion criteria. Consequently, although the survey (questionnaires and refusal documentation) was sent to 115 bereaved families, 10 subjects did not receive the questionnaire due to changed physical addresses. Therefore, effective questionnaires were sent to 105 bereaved families. Of these, 77 returned the survey (73\% response rate), of which 20 participants completed refusal documentation. The reasons for refusal are shown in Figure 1. In total, 57 participants answered the valid and analyzable questionnaires (response rate: $54 \%$ ). The mean duration between patients' death and the questionnaire mailing date was 4.7 years (range: 0.4-9.5 years).

\section{Characteristics of Deceased Patients and Bereaved Families}

The characteristics of the deceased patients and bereaved families are summarized in Table 1.

\section{Prevalence of EOLD}

Table 2 shows the frequency and type of patient participation in EOLDs. Overall, 54\% (31 out of 57) of the deceased patients with HGG participated in EOLDs at least once during the illness trajectory. Additionally, the most frequent types of EOLD participation were as follows: with family members (44\%, 25 out of 57), with family members only (47\%, 27 out of 57), and no history of participation (9\%, 5 out of 57). None of the responses indicated that the patient participated in the EOLD alone, and those who participated in EOLDs did so with their family members. Furthermore, the level of family-only participation was higher than that of patient and family participation.

The reasons for family-only participation $(47 \%, 27$ out of 57) were as follows: "Families were reluctant in making patients aware of the details of their medical conditions" and "patients could not participate in EOLDs because of health deterioration" (26\% and 59\%, respectively). 


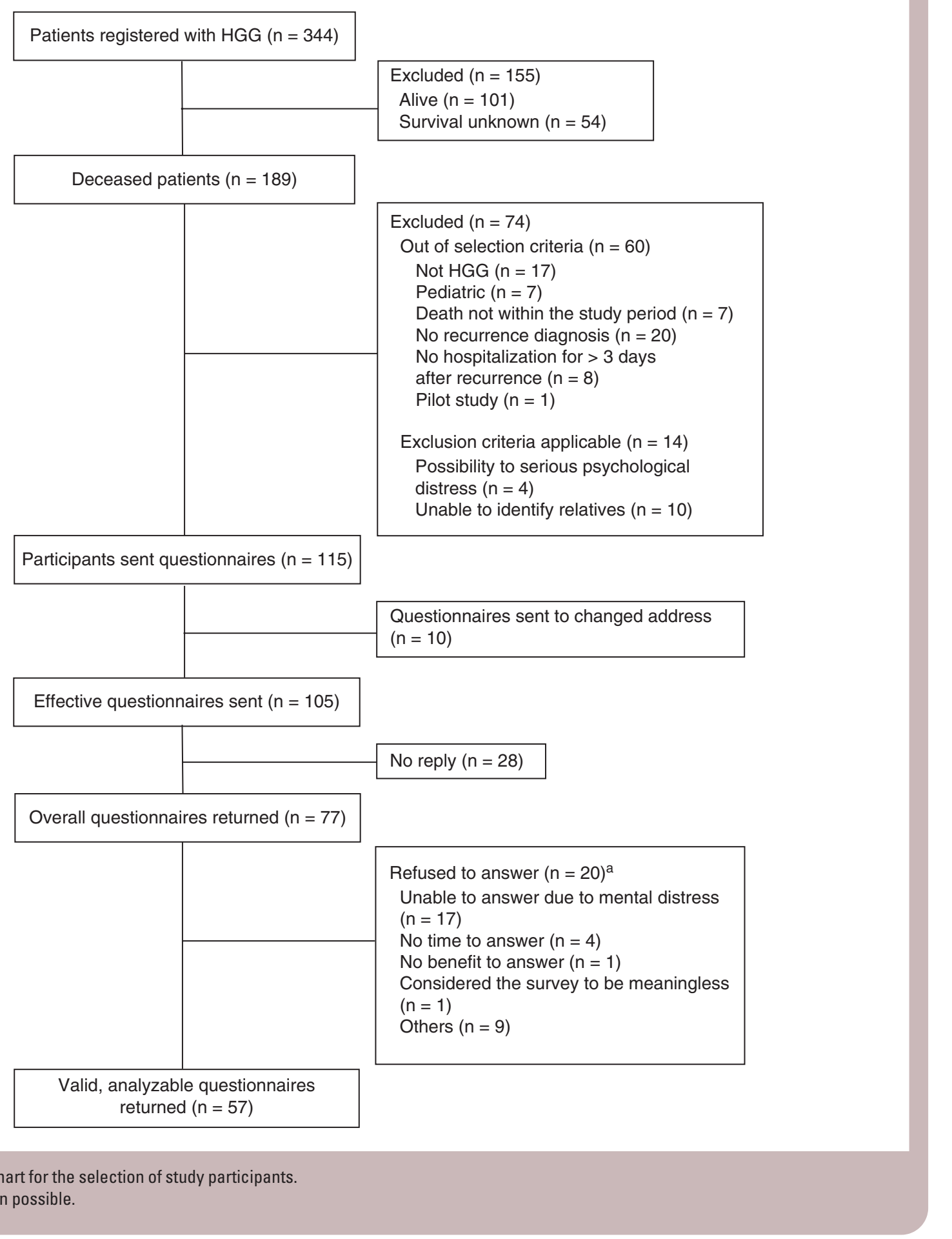

Figure 1. Flowchart for the selection of study participants. ${ }^{a}$ Multiple selection possible.

\section{Details of EOLDs in Patients With HGG}

Table 3 shows the decision-making capacity of the participants, as determined by the relatives, and topics discussed in EOLDs during each phase of EOLD participation. Overall, 76 and 81 cases of EOLDs were performed with and without patients, respectively.

Regarding the transition of decision-making capacity in patients with HGG, the proportion of patients who maintained their decision-making capacity before HGG recurrence was $72 \%$ and $88 \%$ in phases $A$ and $B$, respectively. After recurrence (phase C1-D), the number of patients with decision-making capacity was halved (52\% in phase C1), and the number decreased steadily. In more than half of the cases where EOLD was performed in the absence of patients, patients themselves could not participate, even though they retained their decision-making capacity in the pre-relapse phase (67\% in phase A, $60 \%$ in phase B). 
Table 1. Characteristics of the Patients and Bereaved Families

\section{Patient characteristics $(n=57)$}

Sex, $\mathrm{n}(\%)$

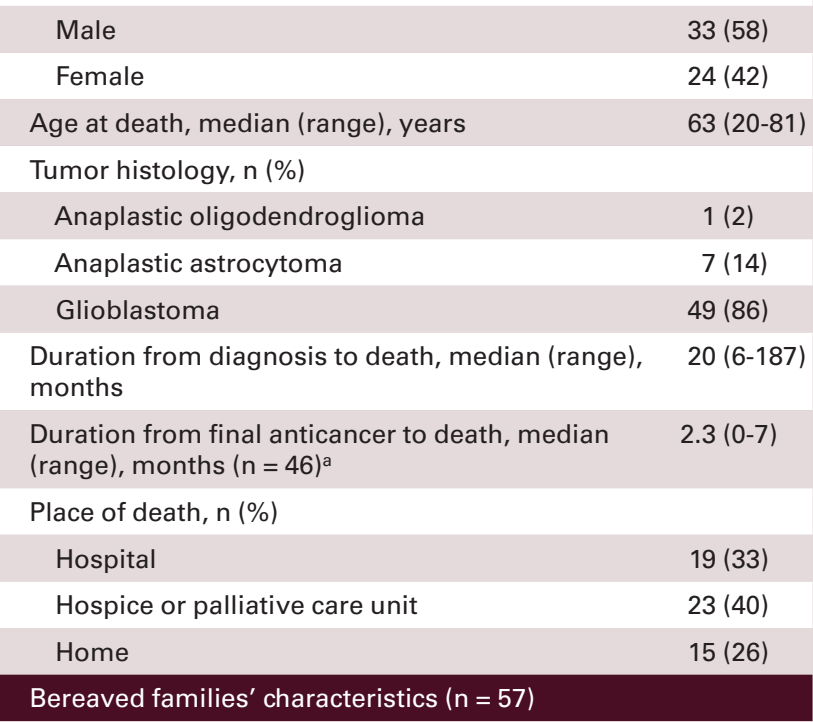

Sex, n (\%)

$\begin{array}{ll}\text { Male } & 16(28) \\ \text { Female } & 41(72)\end{array}$

Age at enrollment, median (range), years

Relationship with patient, $\mathrm{n}(\%)$

\begin{tabular}{lc} 
Spouse & $34(59.6)$ \\
Mother & $10(17.5)$ \\
\hline Father & $2(3.5)$ \\
\hline Sibling & $2(3.5)$ \\
Child & $6(10.5)$ \\
Child-in-low & $1(1.8)$ \\
Other & $2(3.5)$
\end{tabular}

Extent of involvement in decision-making process about treatment and care $\mathrm{n}(\%)$

Complete involvement

Partial involvement

No involvement

altem sample size differed because of data from one facility; the patient transferred to another facility and could no longer be followed.

The major EOLD topics in all phases for both groups were treatment goals and choices, which were discussed in $80 \%$ (61 out of 76 ) and $62 \%$ (50 out of 81 ) of participations with and without patients, respectively. The EOLD topic regarding patient goals and priorities was discussed in only $28 \%$ ( 21 out of 76 ) and $10 \%$ (8 out of 81 ) of participations with and without patients, respectively. The group that participated without patients had a higher rate of discussion of EOL issues than did the group that participated with patients as follows: life-prolonging treatment, $17 \%$ vs $12 \%$; use of PC services for the EOL phase, $58 \%$ vs $20 \%$; preferred place of EOL care, $38 \%$ vs $28 \%$; and preferred place of death, $40 \%$ vs $14 \%$. Thus, EOL
Table 2. Frequency and Type of Patient Participation in EOLDs

Frequency of patient participation in EOLDs $(n=57) \quad n(\%)$

More than once

31 (54)

Never participated

$26(46)$

Type of patient participation in EOLDs $(n=57)$ $\mathrm{n}(\%)$

Patient only

$0(0)$

Patient and family

25 (44)

Family only

$27(47)$

Never participated

5 (9)

Abbreviation: EOLD, end-of-life discussion.

issues were likely to be discussed with family-only participation, thereby lacking consideration of patient goals and priorities.

Although almost all cases of EOLDs in all phases were initiated by a neurosurgeon (96\%, 73 out of 76 in participations with patients; $96 \%, 78$ out of 81 in participations without patients), other HCPs rarely participated in either group (eg, nurses in the neurosurgery department, $32 \%, 14 \%$, and medical social worker, $14 \%, 10 \%$ in participations with and without patients, respectively) (see Supplementary data).

\section{Perception of the Timing of Initiating EOLDs}

The timing of initiating EOLDs for the group that participated with patients was as follows: $n=18(58 \%)$ in phase $A, n=4(13 \%)$ in phase $B, n=6(19 \%)$ in phase $C 1, n=3$ $(10 \%)$ in phase $C 2$, and $n=0(0 \%)$ in phase $D$. The number of EOLD participants decreased over time after initial participation (see Supplementary data). Overall, 1, 3, 12, and 8 of the patients participated in all phases, participated four times, participated three times, and participated twice, respectively. Of the 24 patients who participated multiple times, 17 were from phase $A(71 \%)$. Patients who were considered as multiple participants were more likely to have participated from the start (phase A). We examined the appropriate timing of initiating EOLDs in patients with HGG from bereaved family perspectives. Those who reported that the timing of EOLDs was appropriate were as follows: $83 \%$ (15 out of 18 ), $100 \%$ (4 out of 4 ), $83 \%$ (5 out of 6 ), $67 \%$ ( 2 out of 3 ), and $0 \%(0$ out of 0 ) in phases $A, B, C 1, C 2$, and $D$, respectively. Thus, the bereaved families in this study tended to accept EOLDs early on.

\section{Association Between Patient Participation in EOLDs and EOLD Outcome Measures}

We assessed the impact of patient involvement in EOLDs on four EOLD outcome measures (Table 4). First, 48\% (15 out of 31) of patients who participated in EOLDs had expressed their wishes to family members compared to $8 \%$ (2 out of 26 ) of patients who did not participate. A significant association was observed between the expression of patient EOL wishes to family members and the patients' 
Table 3. Decision-Making Capacity and Topics Discussed in EOLDs in Each Phase by EOLD Participation

\begin{tabular}{|c|c|c|c|c|c|c|c|c|c|c|c|c|}
\hline \multirow{3}{*}{$\begin{array}{l}\text { Phase in the illness } \\
\text { trajectory }{ }^{a}, \mathrm{n}(\%)^{\mathrm{b}}\end{array}$} & \multicolumn{6}{|c|}{ Patient and Family Participated in EOLD } & \multicolumn{6}{|c|}{ Family Only Participated in EOLD } \\
\hline & A & B & $\mathrm{C} 1$ & C2 & D & Total & A & B & $\mathrm{C} 1$ & $\mathrm{C} 2$ & D & Total \\
\hline & $18(55)$ & $17(63)$ & $21(57)$ & $16(42)$ & $4(18)$ & $76(100)$ & $15(45)$ & $10(37)$ & $16(43)$ & $22(58)$ & $18(82)$ & $81(100$ \\
\hline $\begin{array}{l}\text { Patients who kept } \\
\text { decision-making } \\
\text { capacity, } \mathrm{n}(\%)\end{array}$ & $13(72)$ & $15(88)$ & $11(52)$ & $7(44)$ & $1(25)$ & $47(62)$ & $10(67)$ & $6(60)$ & $8(50)$ & $5(23)$ & $5(28)$ & $34(42)$ \\
\hline \multicolumn{13}{|c|}{ Topics discussed in EOLD ${ }^{\mathrm{c}}, \mathrm{n}(\%)$} \\
\hline $\begin{array}{l}\text { Patients' goals and } \\
\text { priorities }\end{array}$ & $6(33)$ & $7(41)$ & $6(29)$ & $2(13)$ & $0(0)$ & $21(28)$ & $1(7)$ & $1(10)$ & $0(0)$ & $4(18)$ & $2(11)$ & $8(10)$ \\
\hline $\begin{array}{l}\text { Treatment goals and } \\
\text { choices }\end{array}$ & $15(83)$ & $14(82)$ & $21(100)$ & $9(56)$ & $2(50)$ & $61(80)$ & $11(73)$ & $7(70)$ & $10(63)$ & $14(64)$ & $8(44)$ & $50(62)$ \\
\hline $\begin{array}{l}\text { Life-prolonging } \\
\text { treatment }\end{array}$ & $2(11)$ & $2(12)$ & $3(14)$ & $2(13)$ & $0(0)$ & $9(12)$ & $3(20)$ & $1(10)$ & $2(13)$ & $5(23)$ & $3(17)$ & $14(17)$ \\
\hline $\begin{array}{l}\text { Use of palliative care } \\
\text { services for EOL phase }\end{array}$ & $2(11)$ & $1(6)$ & $3(14)$ & $7(44)$ & $2(50)$ & $15(20)$ & $12(80)$ & $6(60)$ & $8(50)$ & $13(59)$ & $8(44)$ & $47(58)$ \\
\hline $\begin{array}{l}\text { Preferred place of EOL } \\
\text { care }\end{array}$ & $2(11)$ & $2(12)$ & $7(33)$ & $7(44)$ & $3(75)$ & $21(28)$ & $4(27)$ & $3(30)$ & $7(44)$ & $12(55)$ & $6(33)$ & 31 (38) \\
\hline Preferred place of death & $2(11)$ & $1(6)$ & $3(14)$ & $4(25)$ & $1(25)$ & $11(14)$ & $2(13)$ & $2(20)$ & $3(19)$ & $7(32)$ & 7 (39) & $32(40)$ \\
\hline
\end{tabular}

Abbreviations: EOLD, end-of-life discussion; EOL, end of life.

aPhase in the illness trajectory: A, from diagnosis to end of initial treatment including surgery and chemoradiation; B, during maintenance adjuvant chemotherapy; $\mathrm{C} 1$, recurrence and new treatment, including second and third surgery, chemotherapy, and radiation therapy; $\mathrm{C} 2$, The timing of final tumor-directed treatment; and D, The timing of hospice palliative care and/or life-prolonging treatment during dying phase.

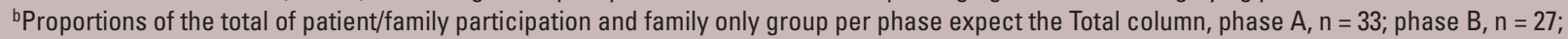
phase $C 1, n=37$; phase $C 2, n=38$; phase $D, n=22$, respectively. Total column shows the total number of EOLD cases per phase.

${ }^{\mathrm{c} M u l t i p l e ~ s e l e c t i o n s ~ p o s s i b l e . ~}$

Table 4. Association Between Patient Participation in End-of-Life Discussions and Their Outcome Measures

\begin{tabular}{|c|c|c|c|c|}
\hline \multirow[b]{2}{*}{ EOLD outcome measures } & \multirow[b]{2}{*}{$\mathrm{n}$} & \multicolumn{3}{|c|}{ Patient Participation in EOLD } \\
\hline & & Present & Absent & $P$ Value \\
\hline $\begin{array}{l}\text { The number of patients who expressed an end-of-life care/treatment } \\
\text { wish by conversation/documentation to families, } \mathrm{n}(\%)\end{array}$ & $57^{a}$ & $15(48)$ & $2(8)$ & $.001^{\mathrm{b}}$ \\
\hline $\begin{array}{l}\text { The number of patients who concorded with place of death and patients' } \\
\text { wisha, } n(\%)\end{array}$ & $57^{a}$ & $20(65)$ & $15(58)$ & $.6^{\mathrm{b}}$ \\
\hline Quality of end-of-life care $(\text { range } 0-100)^{c}$, mean \pm SD & $56^{d}$ & $75.1 \pm 3.1$ & $73.5 \pm 3.5$ & $.47^{\mathrm{e}}$ \\
\hline Quality of death (range $18-126)^{f}$, mean \pm SD & $56^{d}$ & $77.7 \pm 21.4$ & $79.3 \pm 12.2$ & $.73^{\mathrm{e}}$ \\
\hline \multicolumn{5}{|c|}{ 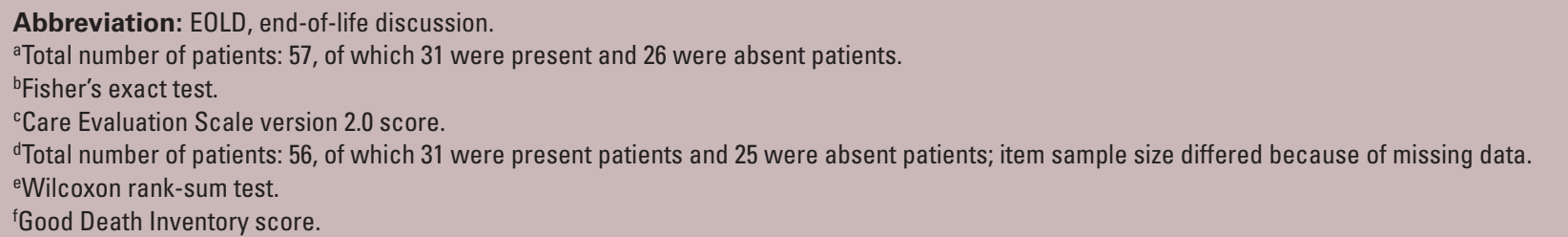 } \\
\hline
\end{tabular}

participation in EOLD $(P=.001)$, as determined by Fisher's exact test yields. In addition, patients who had participated in EOLDs had higher rates of expressing their wishes for EOL care to their families by conversation or documentation. Second, Fisher's exact test showed no significant difference in the proportions of patients who were consistent with the preferred place of death between patient participation and nonparticipation. Next, we assessed the associations between EOLDs and quality of EOL care (CES 2.0) and death (GDI). The mean ( \pm standard deviation [SD]) CES 2.0 scores in this study were $75.1 \pm 3.1$ and $73.5 \pm 3.5$ in the patient participation and nonparticipation groups, respectively. No significant differences were observed in the CES 2.0 scores, regardless of the patients' participation in EOLDs $(P=.47)$. Finally, regarding the quality of death in patients with $\mathrm{HGG}$, the mean $( \pm \mathrm{SD}) \mathrm{GDI}$ scores in this study were $77.7 \pm 21.4$ and $79.3 \pm 12.2$ in the patient participation and nonparticipation groups, respectively. No significant 
difference was observed between patient participation or nonparticipation in EOLDs and the GDI score $(P=.73)$.

\section{Discussion}

To the best of our knowledge, this is the first study, conducted with the help of bereaved families, surveying the appropriateness of the timing and extent of patient involvement in implementing EOLDs for HGG and the impact of these on outcomes, such as the quality of EOL care and a good death. The results suggested that when patients with HGG had the opportunity to participate in EOLDs, approximately half of them could discuss and share their wishes with their families. Furthermore, most of the bereaved families who participated in the study seemed to have had a favorable opinion on EOLD implementation during the early stages of diagnosis. Therefore, HCPs should work collaboratively to involve patients in ACP discussions early in their HGG treatment so that they can participate in the conversation and, if they wish, share "what matters to them."

The present study uncovered several other key findings. While accounting for the need to develop a model of EOLD (ACP) support for patients with HGG, we would like to offer the following suggestions for effective management: Fiftyfour percent of the patients in this study participated in an EOLD at least once in an acute hospital setting. Although the early-stage deterioration of the patients' medical condition often incapacitates patients with HGG from being involved in EOLDs, ${ }^{1}$ more than half of the patients in this study $(67 \%$ in phase $A, 60 \%$ in phase $B)$ who retained their decision-making ability before recurrence did not participate in EOLDs. Twenty-six percent of the participants who selected "family-only participation in the EOLDs" as the most frequent type of involvement reported that they did not want the patients to be aware of the details of their medical condition. In a survey by the Japanese Society of Neuro-Oncology members on the current status of palliative and terminal care for patients with brain tumors in Japan ( $n=154$ ), only $39 \%$ of all patients received the same explanation as their families. This indicates that HCPs and patients' families in Japan tend to be reluctant to tell patients with severe brain tumors the truth about their conditions. Similarly, Yamamoto et al. reported that more than half of physicians respected the family's wishes regarding disclosing diagnosis to patients with glioma. ${ }^{22}$ Unlike in Western countries, where the ACP is developed with an emphasis on the individual's right to self-determination, it is clear that Japan has a cultural background of value judgments that respects the unique relationship between the patient and family, and sometimes the HCPs, with an emphasis on harmony with their surroundings. ${ }^{39,40}$ Although family members' anxiety about causing distress to the patient by telling the truth may be one of the barriers to participation in EOLD, ${ }^{22,41}$ Umezawa et al. suggested that Japanese patients with advanced cancer prefer that their physicians do not prioritize family members alone and want to participate in the decision-making even in the context of advanced disease. ${ }^{42}$ Considering this situation, it is imperative that HCPs explore patients' preferences regarding EOLD engagement. ${ }^{16,17,43}$ Moreover, educational support should be provided to patients (and especially their families) to facilitate patient-family discussions so that patients can see EOLDs as an important opportunity and participate in the discussion. Since many patients with HGG have a diminished decision-making ability closer to their EOL, they eventually have to leave decision-making to their family (proxy). ${ }^{25}$ ACP and EOLDs provide an opportunity to facilitate communication regarding EOL and strengthen relationships with loved ones. ${ }^{44}$ Encouraging communication between patients and families is essential, especially in countries such as Japan, where the culture involves including the family members in decision-making ${ }^{45}$ and there are no established laws regarding the decision-making process. ${ }^{46}$

Participants in the EOLD group that included patient involvement while initiating EOLD were highest in phase A. However, this trend decreased over time. Since most patients are outpatients during phase B, HCPs apart from physicians have fewer opportunities to communicate with them. However, the number of patients with decision-making capacity was halved ( $52 \%$ in phase $\mathrm{C} 1)$ after recurrence, and the proportion continued to decrease steadily thereafter. Moreover, in our previous study that explored glioblastoma patients' experiences starting from diagnosis to recurrence, we observed that patients experienced physical recovery even in daily life with vulnerability, felt a discrepancy between their severe prognosis predicted during diagnosis and their current medical condition, and became less aware of recurrence and/or death. ${ }^{47}$ After disease recurrence, patient participation in EOLDs might be more challenging because of barriers, such as exacerbation of their medical condition, family fears of causing distress to patients, ${ }^{22,41}$ and an increased reluctance of HCPs to provide distressing news. Given that the bereaved families in this study approved of introducing EOLDs to patients with HGG and their caregivers from diagnosis to end of initial treatment, including surgery and chemoradiation (83\%, phase A), HCPs should facilitate patient participation in EOLDs from phase A. However, the implementation of EOLDs in line with individual patients' and families' readiness and preferences to engagement is essential. ${ }^{17,43}$

No significant difference in the quality of EOL care (CES 2.0) and death (GDI) was observed between the groups with and without patient participation in EOLDs. Similarly, our results showed no significant difference in the rates of the place of death concordant with patients' wishes, between patient participation and nonparticipation groups. There are three possible reasons for these results. Firstly, patients in this study had a lower home death rate $(26 \%)$ and the highest number of deaths in hospice $(40 \%)$ compared to three European countries (the Netherlands, Austria, and the UK). ${ }^{48}$ Even if patients with HGG, especially in Japan, express their preferences for the place of EOL care and death, they are likely to die in a hospice or palliative care unit (PCU) since they become increasingly dependent on others for activities of daily living at the EOL stage. In the Japanese National Bereaved Families Survey, $94 \%$ ( $n=5820$ ) of relatives were satisfied with their care in PCUs, and overall, bereaved families were highly satisfied with the care they received. ${ }^{49}$ Additionally, there were few regional differences in the quality of perceived 
PC in PCUs in Japan. ${ }^{50}$ Thus, EOLDs may not be expected to affect the quality of EOL care and death among patients with HGG. If EOLDs are initiated earlier (during initial treatment), it may be possible to aim for home hospice care, and HCPs should collaborate to support the initiation of EOLDs. Second, patients and families in this study exclusively discussed their options regarding the realities they were confronted; thus, the EOLD quality might not have been sufficient. A previous report regarding patients with advanced cancer hospitalized in a PCU or hospice in Japan showed that the CES and GDI scores were significantly higher in the participation than in the nonparticipation group. ${ }^{33}$ Although about half of the patients in this study participated in EOLD, and more than $70 \%$ of the patients who participated early in their diagnosis were able to participate more than once, a significant majority of the EOLDs were held by neurosurgeons with a very low rate of PC specialists involvement in all phases of the illness trajectory. Discussions were led solely by the neurosurgeon, and only $28 \%$ of EOLDs included a topic on patient goals and priorities; additionally, the opportunity for discussing EOL issues appeared more often without patient participation. A previous large intervention study suggested that PC interventions relying on one set of professionals hardly improve EOL patient outcomes. ${ }^{51}$ Especially in Japan, patients with HGG are primarily managed by general neurosurgeons (93\%, $\mathrm{n}=154$ ), and this is extremely common compared to Europe $21 \%(n=75)$ and the United States/ Canada $27 \%$ ( $n=164) .52$ Surgical neuro-oncologists are not always responsible for the diagnosis or treatment of these patients. ${ }^{22}$ Moreover, a few neuro-oncologists and nurses specialize in neuro-oncologic care in Japanese neurosurgery departments, and HCPs have more opportunities to care for patients other than those with malignant neoplasms, such as patients with acute stroke. Thus, HCPs caring for patients with HGG, especially in Japan, may not develop PC and ACP communication skills. Regular and organic early implementation of EOLD by a multidisciplinary team as part of PC may have a positive effect on the quality of care and death. Therefore, HCPs should be educated regarding the necessity of multi-professional collaboration and communication skills to help them implement EOLDs respecting patients' goals and priorities in interdisciplinary teams. Finally, as HGG patients at EOL often have difficulty in expressing their thoughts and wishes, the fact that their bereaved families responded with estimates of the quality of EOL care and death of the patients may have strongly influenced the CES and GDI scores. In this study, the median duration of decedents from anticancer treatment withdrawal to death was 2.3 months. Patients with HGG tended to be conscious but found it impossible to communicate as death approaches. Patients with other general cancers may often express their wishes just before death. ${ }^{2-4}$ In a previous retrospective study by Koekkoek et al. that focused on the examination of EOL care in HGG patients in three European countries, it was reported that bereaved families who were required to answer the questionnaire appeared to be occasionally unaware of some of the deceased patient's answers, possibly because of the patient's cognitive disturbances or somnolence, which might have interfered severely with communication. ${ }^{48}$ Particularly, the GDI requires the bereaved family to assume the deceased patient's perspectives at the EOL phase. Thus, further intervention studies are needed to clarify the impact of EOLDs on the quality of EOL care and death.

Our study has a few limitations. First, the reported responses of the bereaved families reflect the experiences at one large university hospital in Kyoto, one of the biggest cities in Japan, and may not apply to patients with HGG and their families in smaller hospitals, in other parts of the world, that do not provide standard treatment and care. Second, the quality of EOL care and death for end-stage cancer patients is commonly assessed by surveying the bereaved family since it is difficult to interview the critically ill patients themselves. ${ }^{37}$ Although we assumed the bias of the bereaved family's report, subjective evaluation of the bereaved family may have affected the findings more than expected because most patients had difficulty communicating close to EOL. Third, the relatives of patients who died between October 2007 and February 2019 were approached for participation. This resulted in a mean duration between the patients' death and the assessment of 4.7 years, ranging between 0.4 and 9.5 years. A significant degree of recall bias may have occurred during this period since the perception of EOLD may have changed after an extended period and may be different for caregivers of patients who had died recently. Fourth, our questionnaire was not validated in previous studies, and our sample size was relatively small. Fifth, it is not possible to retrospectively verify whether the patients alone participated in EOLD because the family may not have known of the patient's involvement. Sixth, a key requirement within the inclusion criteria for deceased patients was a history of hospitalization at Kyoto University Hospital for more than 3 days until death after HGG recurrence. In summary, we believe that these factors affect the generalizability of our results since we might have excluded patients for whom EOLDs had been discussed early in the trajectory. Seventh, $46 \%(n=48)$ of the relatives who were sent the questionnaire did not complete it, which might have introduced a selection bias in the results. Finally, it is possible that patients and families did not participate in quality EOLDs provided to the subjects in this study because the attending physicians, who did not have the advanced and sophisticated communication skills of PC specialists, explained the outlook and treatment options based on standard skills. This may have negatively impacted the results of CES 2.0 and GDI.

In conclusion, in our study, $54 \%$ of patients participated in an EOLD at least once in an acute hospital setting. Although no significant difference was observed between EOLDs and the quality of EOL care and death, even in patients with HGG for whom EOLD implementation is challenging, patient participation in EOLDs could enable approximately half of the patients to express their wishes to their families. Most bereaved families in the patient participation group accepted early initiation of EOLD. However, only $28 \%$ of EOLDs reflected patient goals and priorities. Most EOLDs were held by neurosurgeons; other HCPs rarely participated. Using an interdisciplinary team approach to EOLD at a relatively early stage after diagnosis may promote patient-initiated participation. However, further research is needed to identify specific strategies to 
effectively integrate ACP (EOLD) into the clinical practice of neuro-oncology care.

\section{Supplementary Material}

Supplementary material is available at Neuro-Oncology Practice online.

\section{Funding}

This study was supported by the Sasakawa Health Foundation (2019A-007).

\section{Acknowledgments}

The authors would like to thank the participating deceased patients with HGG and their bereaved families for their time and effort in completing the questionnaire.

Conflict of interest statement. The authors declare no potential conflicts of interest.

\section{References}

1. Sizoo EM, Pasman HR, Buttolo J, et al. Decision-making in the end-of-life phase of high-grade glioma patients. Eur J Cancer. 2012;48(2):226-232.

2. Fritz $\mathrm{L}$, Dirven $\mathrm{L}$, Reijneveld J, et al. Advance care planning in glioblastoma patients. Cancers (Basel). 2016;8(11):102.

3. Pace A, Walbert T. Simultaneous care in neuro-oncology. Neuro Oncol. 2018;20(3):302-303

4. Philip J, Collins A, Brand CA, et al. Health care professionals' perspectives of living and dying with primary malignant glioma: implications for a unique cancer trajectory. Palliat Support Care. 2015;13(6):1519-1527.

5. Moore G, Collins A, Brand C, et al. Palliative and supportive care needs of patients with high-grade glioma and their carers: a systematic review of qualitative literature. Patient Educ Couns. 2013;91(2):141-153.

6. Walbert T. Palliative care, end-of-life care, and advance care planning in neuro-oncology. Continuum (Minneap Minn). 2017;23(6, Neuro-onco logy):1709-1726.

7. Jacobs DI, Kumthekar P, Stell BV, et al. Concordance of patient and caregiver reports in evaluating quality of life in patients with malignant gliomas and an assessment of caregiver burden. Neurooncol Pract. 2014;1(2):47-54.

8. Dirven L, Sizoo EM, Taphoorn MJ. Anaplastic gliomas: end-of-life care recommendations. CNS Oncol. 2015;4(5):357-365.

9. Sudore RL, Pollom EL, Asch SM, Soltys SG, Sborov KD, Aslakson RA. Advance care planning needs in patients with glioblastoma undergoing radiotherapy. J Pain Symptom Manage. 2018;56(6):e6-e8.
10. Narita Y, Shibui S. From data collection to clinical trials: establishing evidences of brain tumors. Japanese J Neurosurg. 2015;24(10):699-704.

11. Pace A, Koekkoek JAF, van den Bent MJ, et al. Determining medical decision-making capacity in brain tumor patients: why and how? Neurooncol Pract. 2020;7(6):599-612.

12. Temel JS, Greer JA, Muzikansky A, et al. Early palliative care for patients with metastatic non-small-cell lung cancer. $N$ Engl J Med. 2010;363(8):733-742.

13. Walbert T. Integration of palliative care into the neuro-oncology practice: patterns in the United States. Neurooncol Pract. 2014;1(1):3-7.

14. McKenzie N, Mirfin-Veitch B, Conder J, et al. "I'm still here": exploring what matters to people with intellectual disability during advance care planning. J Appl Res Intellect Disabil. 2017;30(6):1089-1098.

15. Ferrell BR, Temel JS, Temin S, et al. Integration of palliative care into standard oncology care: American Society of Clinical Oncology clinical practice guideline update. J Clin Oncol. 2017;35(1):96-112.

16. Rietjens JAC, Sudore RL, Connolly M, et al.; European Association for Palliative Care. Definition and recommendations for advance care planning: an international consensus supported by the European Association for Palliative Care. Lancet Oncol. 2017;18(9):e543-e551.

17. Brighton LJ, Bristowe K. Communication in palliative care: talking about the end of life, before the end of life. Postgrad Med J. 2016;92(1090):466-470.

18. Kadowaki M. A concept analysis of end-of-life discussions with cancer patients. J Japan Acad Nurs Sci. 2016;36:263-272.

19. Miranda SP, Bernacki RE, Paladino JM, et al. A descriptive analysis of end-of-life conversations with long-term glioblastoma survivors. Am J Hosp Palliat Care. 2018;35(5):804-811.

20. Flechl B, Ackerl M, Sax C, et al. The caregivers' perspective on the end-oflife phase of glioblastoma patients. J Neurooncol. 2013;112(3):403-411.

21. Abarshi E, Echteld M, Donker G, et al. Discussing end-of-life issues in the last months of life: a nationwide study among general practitioners. J Palliat Med. 2011;14(3):323-330.

22. Yamamoto F, Hashimoto N, Kagawa $\mathrm{N}$, et al. A survey of disclosure of diagnosis to patients with glioma in Japan. Int $\mathrm{J}$ Clin Oncol. 2011;16(3):230-237.

23. Llewellyn H, Neerkin J, Thorne L, et al. Social and structural conditions for the avoidance of advance care planning in neuro-oncology: a qualitative study. BMJ Open. 2018;8(1):e019057.

24. Narita Y, Miyakita Y, Momota H, Miyahara R, Shibui S. A survey of neurosurgeons' policies and attitudes regarding the disclosure of a diagnosis of glioma and the decision to pursue end-of-life care in glioma patients. Neurol Surg. 2009:37(10):973-981.

25. Schofield HL, Murphy B, Herrman HE, et al. Family caregiving: measurement of emotional well-being and various aspects of the caregiving role. Psychol Med. 1997;27(3):647-657.

26. Song K, Amatya B, Voutier C, et al. Advance care planning in patients with primary malignant brain tumors: a systematic review. Front Oncol. 2016:6:223.

27. Tariman JD, Berry DL, Cochrane B, et al. Preferred and actual participation roles during health care decision making in persons with cancer: a systematic review. Ann Oncol. 2010;21(6):1145-1151.

28. Sizoo EM, Taphoorn MJ, Uitdehaag B, et al. The end-of-life phase of high-grade glioma patients: dying with dignity? Oncologist. 2013;18(2):198-203

29. Pace A, Dirven L, Koekkoek JAF, et al.; European Association of NeuroOncology Palliative Care Task Force. European Association for NeuroOncology (EANO) guidelines for palliative care in adults with glioma. Lancet Oncol. 2017;18(6):e330-e340.

30. Iwabuchi M, Sato K, Miyashita M, Morita T, Kinoshita H. Factors that influence the decision maker regarding end-of-life care. Palliat Care Res. 2016;11(2):189-200. 
31. Kinoshita H, Maeda I, Morita T, et al. Place of death and the differences in patient quality of death and dying and caregiver burden. J Clin Oncol. 2015;33(4):357-363.

32. Mack JW, Weeks JC, Wright AA, et al. End-of-life discussions, goal attainment, and distress at the end of life: predictors and outcomes of receipt of care consistent with preferences. J Clin Oncol. 2010;28(7):1203-1208.

33. Yamaguchi T, Maeda I, Hatano Y, et al. Effects of end-of-life discussions on the mental health of bereaved family members and quality of patient death and care. J Pain Symptom Manage. 2017:54(1):1726.e1.

34. Philip J, Collins A, Brand C, et al. A proposed framework of supportive and palliative care for people with high-grade glioma. Neuro Oncol. 2018;20(3):391-399.

35. Miyashita M, Aoyama M, Nakahata M, et al. Development the Care Evaluation Scale Version 2.0: a modified version of a measure for bereaved family members to evaluate the structure and process of palliative care for cancer patient. BMC Palliat Care. 2017;16(1):8.

36. Shin DW, Choi JE, Miyashita M, et al. Measuring the structure and process of end-of-life care in Korea: validation of the Korean version of the Care Evaluation Scale (CES). J Pain Symptom Manage. 2012;44(4):615-625.e2.

37. Miyashita M, Morita T, Sato K, et al. Good Death Inventory: a measure for evaluating good death from the bereaved family member's perspective. J Pain Symptom Manage. 2008;35(5):486-498.

38. Shin DW, Choi J, Miyashita M, et al. Measuring comprehensive outcomes in palliative care: validation of the Korean version of the Good Death Inventory. J Pain Symptom Manage. 2011;42(4):632-642.

39. Tanimoto M, Akuta Y, Shigeta I. Integrative review of advance care planning research in Japan. Palliat Care Res. 2018;13(4):341-355.

40. Bagheri A. Medical Futility: A Cross-National Study. London: Imperial College Press; 2013.

41. Barnes K, Jones L, Tookman A, et al. Acceptability of an advance care planning interview schedule: a focus group study. Palliat Med. 2007;21(1):23-28.
42. Umezawa S, Fujimori M, Matsushima E, et al. Preferences of advanced cancer patients for communication on anticancer treatment cessation and the transition to palliative care. Cancer. 2015;121(23):4240-4249.

43. Fritz $L$, Zwinkels $H$, Koekkoek JAF, et al. Advance care planning in glioblastoma patients: development of a disease-specific ACP program. Support Care Cancer. 2020;28(3):1315-1324.

44. Martin DK, Emanuel LL, Singer PA. Planning for the end of life. Lancet. 2000;356(9242):1672-1676.

45. Markus HR, Kitayama S. Culture and the self: implications for cognition, emotion, and motivation. Psychol Rev. 1991;98(2):224-253. https://web. stanford.edu/ hazelm/publications/1991 Markus Kitayama Culture and the self.pdf

46. Watanabe Y, Hirakata H, Okada K, et al. Proposal for the shared decision-making process regarding initiation and continuation of maintenance hemodialysis. Ther Apher Dial. 2015;19(Supplement 1):108-117.

47. Chikada A, Takekuma Katsumata A, Asase M, Takenouchi S, Arakawa Y, Nin K. Lived experience in patients with recurrent glioblastoma in Japan: a narrative study. Asian/Pacific /s/ Nurs J. 2017;2(4):157-165.

48. Koekkoek JAF, Dirven L, Reijneveld JC, et al. End of life care in highgrade glioma patients in three European countries: a comparative study. J Neurooncol. 2014;120(2):303-310.

49. Shimizu M, Aoyama M, Morita T, Tsuneto S, Shima Y, Miyashita M. A second time nationwide survey of quality of end-of-life cancer care in general hospitals, inpatient palliative care units, and clinics in Japan: the J-HOPE 2 study. Palliat Care Res. 2016;11(4):254-264.

50. Yonenaga Y, Aoyama M, Moriya Y, et al. Regional differences in quality of care at palliative care units (PCUs), and complicated grief and depression of bereaved family members: results from a nationwide bereavement survey in Japan. Palliat Care Res. 2018;13(3):235-243.

51. Connors AF. A controlled trial to improve care for seriously III hospitalized patients: the study to understand prognoses and preferences for outcomes and risks of treatments (SUPPORT). JAMA. 1995;274(20):1591.

52. Aoki T, Narita Y, Mishima K, et al. Current status of palliative and terminal care for patients with primary malignant brain tumors in Japan. Neurol Med Chir (Tokyo). 2020;60(12):600-611. 


\section{Supplements}

Supplementary Table 1. Health care provider who participated in EOLDs in each phase and EOLD participation

\begin{tabular}{|c|c|c|c|c|c|c|c|c|c|c|c|c|}
\hline \multirow{3}{*}{$\begin{array}{l}\text { Phase of the } \\
\text { illness } \\
\text { trajectory }^{\text {a }}\end{array}$} & \multicolumn{6}{|c|}{ Patient and family participated in EOLD } & \multicolumn{6}{|c|}{ Family only participated in EOLD } \\
\hline & \multirow[t]{2}{*}{ A } & \multirow[t]{2}{*}{$\mathrm{B}$} & \multirow[t]{2}{*}{$\mathrm{C} 1$} & \multirow[t]{2}{*}{$\mathrm{C} 2$} & \multirow[t]{2}{*}{$\mathrm{D}$} & \multirow[t]{2}{*}{ Total } & \multirow[t]{2}{*}{$\mathrm{A}$} & \multirow[t]{2}{*}{ B } & \multirow[t]{2}{*}{$\mathrm{C} 1$} & \multirow[t]{2}{*}{$\mathrm{C} 2$} & \multirow[t]{2}{*}{$\mathrm{D}$} & \multirow[t]{2}{*}{ Total } \\
\hline & & & & & & & & & & & & \\
\hline$n(\%)^{b}$ & $18(55)$ & $17(63)$ & $21(57)$ & $16(42)$ & $4(18)$ & $76(100)$ & $15(45)$ & $10(37)$ & $16(43)$ & $22(58)$ & $18(82)$ & $81(100)$ \\
\hline \multicolumn{13}{|l|}{ Health care } \\
\hline \multicolumn{13}{|l|}{ provider who } \\
\hline \multicolumn{13}{|l|}{ participated } \\
\hline \multicolumn{13}{|l|}{ in EOLD, $\mathrm{n}$} \\
\hline \multicolumn{13}{|l|}{$(\%)^{a}$} \\
\hline Neurosurg & $17(94)$ & $17(100)$ & $21(100)$ & $14(88)$ & $4(100)$ & $73(96)$ & $15(100)$ & $9(90)$ & $15(94)$ & $22(100)$ & $17(94)$ & $78(96)$ \\
\hline \multicolumn{13}{|l|}{ eon } \\
\hline Nurse in & $6(33)$ & $6(35)$ & $7(33)$ & $5(31)$ & $0(0)$ & $24(32)$ & $3(20)$ & $1(10)$ & $2(13)$ & $2(9)$ & $3(17)$ & $11(14)$ \\
\hline
\end{tabular}


neurosurge

ry

department

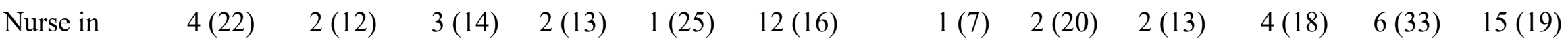

the

community

healthcare

coordinatio

n unit

Outpatient

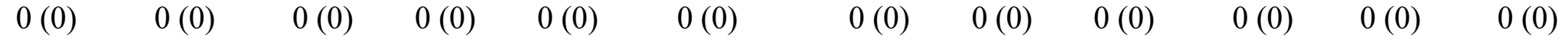

nurse

Physician

$2(11) \quad 2(12)$

$1(5) \quad 2(13)$

$0(0)$

7 (9)

$1(7) \quad 2(20) \quad 4(25)$

$1(5) \quad 1(6)$

$9(11)$

in the

palliative

care team 


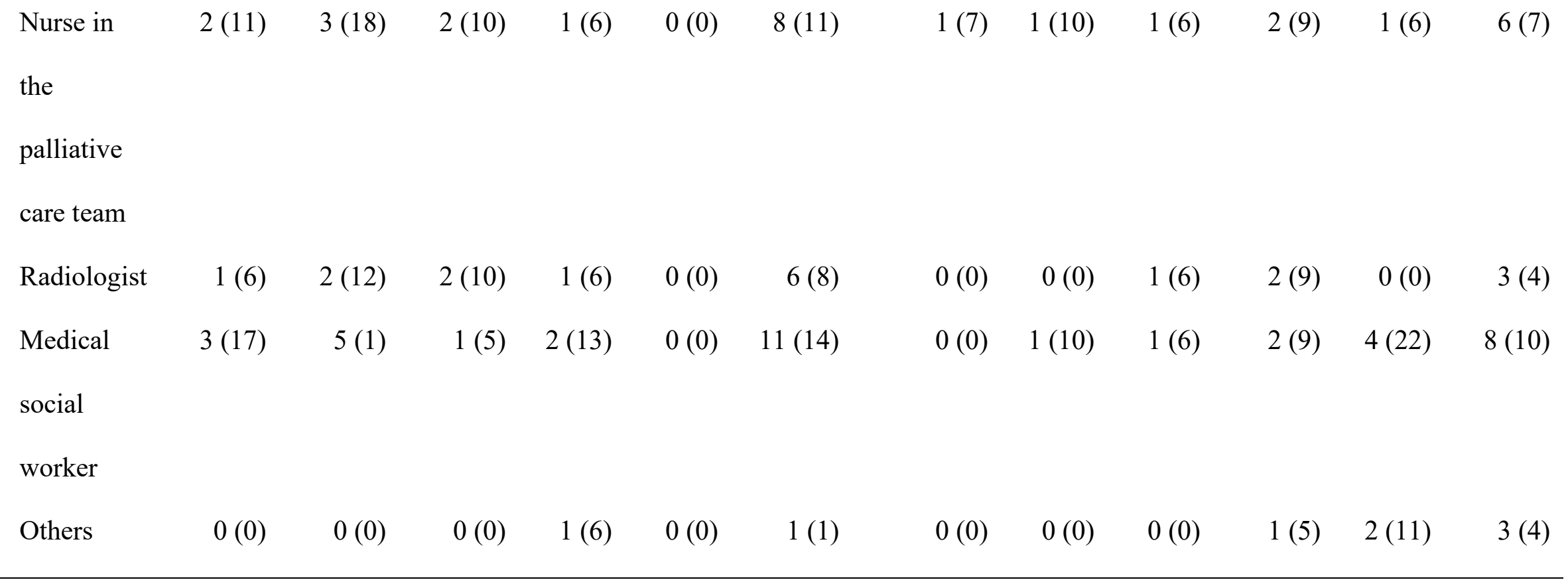

Abbreviations: EOLD, End-of-Life Discussion; EOL, End-of-Life

${ }^{a}$ Multiple selection possible. Phase in the illness trajectory: A, from diagnosis to end of initial treatment including surgery and chemoradiation; $\mathrm{B}$, during maintenance adjuvant chemotherapy; $\mathrm{C} 1$, recurrence and new treatment, including second and third surgery, chemotherapy, and radiation therapy; $\mathrm{C} 2$, the timing of final tumor-directed treatment; and D, the timing of hospice palliative care and/or life-prolonging treatment during the dying phase. 
${ }^{b}$ Proportions of the total of patient/ family participation and family only group per phase except the Total column, phase A, $\mathrm{n}=33$; phase $B, n=27$; phase $C 1, n=37$; phase $C 2, n=38$; phase $D, n=22$, respectively. Total column shows the total number of EOLD cases per phase. 
Supplementary Table 2. Perception of the timing of EOLDs in each phase

\begin{tabular}{|c|c|c|c|c|c|c|c|c|c|c|}
\hline Phase in the illness & \multicolumn{2}{|c|}{$\mathrm{A}$} & & & \multicolumn{2}{|c|}{$\mathrm{C} 1$} & \multicolumn{2}{|c|}{$\mathrm{C} 2$} & \multicolumn{2}{|l|}{$\mathrm{D}$} \\
\hline Total patients & 18 & 18 & 17 & 4 & 21 & 6 & 16 & 3 & 4 & 0 \\
\hline \multicolumn{11}{|c|}{ participated in EOLDs / } \\
\hline \multicolumn{11}{|c|}{ patients participated in } \\
\hline \multicolumn{11}{|c|}{ EOLDs for the first time, } \\
\hline \multicolumn{11}{|l|}{ No. } \\
\hline \multicolumn{11}{|c|}{ Perception of the timing } \\
\hline \multicolumn{11}{|l|}{ of EOLD, n (\%) } \\
\hline Too early & $1(6)$ & $1(6)$ & $1(6)$ & $0(0)$ & $0(0)$ & $0(0)$ & $0(0)$ & $0(0)$ & $0(0)$ & $0(0)$ \\
\hline Appropriate & $15(83)$ & $15(83)$ & $16(94)$ & $4(100)$ & $19(90)$ & $5(83)$ & $13(81)$ & $2(67)$ & $4(100)$ & $0(0)$ \\
\hline Little bit late & $2(11)$ & $2(11)$ & $0(0)$ & $0(0)$ & $2(10)$ & $1(17)$ & $3(19)$ & $1(33)$ & $0(0)$ & $0(0)$ \\
\hline Too late & $0(0)$ & $0(0)$ & $0(0)$ & $0(0)$ & $0(0)$ & $0(0)$ & $0(0)$ & $0(0)$ & $0(0)$ & $0(0)$ \\
\hline
\end{tabular}

Abbreviations: EOLD, End-of-Life Discussion; EOL, End-of-Life 
${ }^{\text {a }}$ Phase in the illness trajectory: A, from diagnosis to end of initial treatment including surgery and chemoradiation; B, during maintenance adjuvant chemotherapy; $\mathrm{C} 1$, recurrence and new treatment, including second and third surgery, chemotherapy, and radiation therapy; $\mathrm{C} 2$, the timing of final tumor-directed treatment; and $\mathrm{D}$, the timing of hospice palliative care and/or life-prolonging treatment during the dying phase. 
Supplementary Table 3. Details of the association between patient participation in EOLDs and quality of EOL care

\begin{tabular}{|c|c|c|c|c|}
\hline \multirow[b]{2}{*}{ Care evaluation scale version 2.0} & \multicolumn{4}{|c|}{ Patient participation in EOLD } \\
\hline & $\begin{array}{l}\text { Total } \\
(n=56)\end{array}$ & $\begin{array}{l}\text { Present } \\
(n=31)\end{array}$ & $\begin{array}{l}\text { Absent } \\
(n=25)\end{array}$ & P-value \\
\hline $\begin{array}{l}\text { 1. Physicians endeavored to relieve physical discomfort of the } \\
\text { patient }\end{array}$ & $4.5 \pm 1.7$ & $4.5 \pm 0.3$ & $4.6 \pm 0.4$ & 0.68 \\
\hline $\begin{array}{l}\text { 2. Nurses endeavored to relieve physical discomfort of the } \\
\text { patient }\end{array}$ & $4.5 \pm 1.7$ & $4.6 \pm 0.3$ & $4.5 \pm 0.3$ & 0.58 \\
\hline $\begin{array}{l}\text { 3. Physicians, nurses and staff endeavored to relieve patients' } \\
\text { concerns and worries. }\end{array}$ & $4.5 \pm 1.6$ & $4.6 \pm 0.3$ & $4.4 \pm 0.3$ & 0.60 \\
\hline $\begin{array}{l}\text { 4. Physicians gave sufficient explanation to the patient about } \\
\text { condition and the medical treatment }\end{array}$ & $3.1 \pm 2.3$ & $3.8 \pm 2.1$ & $2.3 \pm 2.3$ & $0.01^{\mathrm{c}}$ \\
\hline $\begin{array}{l}\text { 5. Physician gave sufficient explanation to the family about } \\
\text { condition and the medical treatment }\end{array}$ & $4.6 \pm 1.4$ & $4.5 \pm 1.7$ & $4.8 \pm 1.1$ & 1.0 \\
\hline 6. Hospital or room was convenient and comfortable & $4.9 \pm 1.1$ & $4.7 \pm 0.2$ & $5.0 \pm 0.2$ & 0.71 \\
\hline 7. Consideration was given to the health of family & $4.5 \pm 1.3$ & $4.6 \pm 0.2$ & $4.3 \pm 0.3$ & 0.31 \\
\hline 8. The total cost is reasonable & $4.4 \pm 1.5$ & $4.3 \pm 0.3$ & $4.5 \pm 0.3$ & 0.93 \\
\hline 9. Admission (use) is possible when necessary without waiting & $4.7 \pm 1.3$ & $4.6 \pm 0.2$ & $4.9 \pm 0.3$ & 0.65 \\
\hline
\end{tabular}


10. There is good cooperation among staff members such as physicians and nurses

Q1-10 total score ${ }^{\mathrm{d}}$

Abbreviations: EOLD, End-of-Life Discussion; EOL, End-of-Life

${ }^{\text {a }}$ One missing data set

${ }^{\mathrm{b}}$ Wilcoxon rank sum test

${ }^{\mathrm{c}} \mathrm{P}<0.05$

d 100-point conversion 
Patient participation in EOLD

Good death inventory, mean $\pm \mathrm{SD}$

\begin{tabular}{|c|c|c|c|}
\hline $\begin{array}{c}\text { Total } \\
(\mathrm{n}=56)^{\mathrm{a}}\end{array}$ & $\begin{array}{l}\text { Present } \\
(n=31)\end{array}$ & $\begin{array}{l}\text { Absent } \\
(n=25)\end{array}$ & P-value ${ }^{b}$ \\
\hline $4.6 \pm 1.7$ & $4.6 \pm 1.8$ & $4.5 \pm 1.6$ & 0.74 \\
\hline $4.8 \pm 1.7$ & $4.8 \pm 1.8$ & $4.9 \pm 1.6$ & 0.82 \\
\hline $4.1 \pm 1.8$ & $4.1 \pm 0.3$ & $4.1 \pm 0.4$ & 0.99 \\
\hline $5.6 \pm 1.5$ & $5.4 \pm 1.8$ & $5.9 \pm 1.0$ & 0.72 \\
\hline $4.2 \pm 1.5$ & $4.5 \pm 1.5$ & $3.9 \pm 1.4$ & 0.09 \\
\hline $5.3 \pm 1.6$ & $5.3 \pm 1.6$ & $5.4 \pm 1.7$ & 0.64 \\
\hline $2.5 \pm 1.8$ & $2.6 \pm 1.8$ & $2.4 \pm 1.9$ & 0.71 \\
\hline $5.5 \pm 1.3$ & $5.4 \pm 1.4$ & $5.6 \pm 1.1$ & 0.71 \\
\hline $5.71 \pm 1.51$ & $5.3 \pm 1.8$ & $6.3 \pm 0.8$ & $0.02^{\mathrm{c}}$ \\
\hline $3.8 \pm 2.0$ & $3.7 \pm 2.2$ & $4.0 \pm 1.9$ & 0.58 \\
\hline $4.7 \pm 1.6$ & $4.5 \pm 1.8$ & $5.0 \pm 1.3$ & 0.40 \\
\hline $4.7 \pm 1.6$ & $4.4 \pm 1.7$ & $5.1 \pm 1.3$ & 0.12 \\
\hline $3.7 \pm 1.9$ & $4.1 \pm 2.1$ & $3.3 \pm 1.5$ & 0.16 \\
\hline
\end{tabular}


14. Knowing what to expect about one's condition in the future
$3.5 \pm 1.8$

$3.6 \pm 1.8$

$4.1 \pm 1.5$

$4.7 \pm 1.6$

$3.2 \pm 2.6$

$78.4 \pm 17.8$
$4.1 \pm 1.8$

$2.8 \pm 1.6$

$0.006^{\mathrm{c}}$

15. Dying without awareness that one is dying

16. Not exposing one's physical and mental weakness to family

17. Feeling that one's life is worth living

18. Supported by religion

Q1-18 total score

Abbreviations: EOLD, End-of-Life Discussion

${ }^{a}$ One missing data set

${ }^{\mathrm{b}}$ Wilcoxon rank sum test

${ }^{\mathrm{c}} \mathrm{P}<0.05$

\begin{tabular}{lll}
$3.5 \pm 1.9$ & $3.8 \pm 1.5$ & 0.50 \\
$4.1 \pm 1.5$ & $4.0 \pm 1.5$ & 0.95 \\
$4.6 \pm 1.7$ & $4.8 \pm 1.5$ & 0.78 \\
$3.0 \pm 1.9$ & $3.5 \pm 2.2$ & 0.36 \\
$77.7 \pm 21.4$ & $79.3 \pm 12.2$ & 0.73 \\
\hline
\end{tabular}

0.50

78 
Supplementary Table 5. Associations between the Quality of End of Life care and death and other variables (univariate analysis) EOL care / treatment wish

express to families

with patients' wish

$\mathrm{n}$

$\begin{array}{cccccccccc}\text { Yes } & \text { No } & \text { P- } & \text { Home } & \text { Hospice/ } & \text { Hospital } & \text { P- } & \text { Consist } & \text { Inconsist } & \text { P- } \\ (n=17) & (n=39) & \text { value } & (n=14) & \text { PCU } & (n=19) & \text { value } & \text { ency } & \text { ency } & \text { value } \\ & & & & & & & & \\ & & & & & & & & \\ & & & & & & & & \end{array}$

Quality of EOL

$56^{\mathrm{b}}$

$78.1 \pm$

$72.7 \pm$

$0.23^{\mathrm{c}}$

$78.3 \pm$

$78.8 \pm$

$66.1 \pm$

$0.07^{\mathrm{d}}$

$18.4 \quad 16.7$

13.9

14.0

20.4

12.7

$69.4 \pm$

$100)^{\mathrm{a}}$

mean $\pm \mathrm{SD}$

Quality of death

$56^{\mathrm{b}} \quad 86.2 \pm \quad 75 \pm \quad 0.03^{\mathrm{c}}$

(range 18-126) ${ }^{\mathrm{e}}$,

mean $\pm \mathrm{SD}$

$19.6 \quad 16.0$

$86.4 \pm$

$79.7 \pm$

$71.1 \pm 0.09^{\mathrm{d}}$

$80.9 \pm$

$74.6 \pm$

$0.3^{\mathrm{c}}$

Abbreviations: EOL, End-of-Life; PCU, Palliative care unit

${ }^{a}$ Care Evaluation Scale version 2.0 score

${ }^{\mathrm{b}}$ one missing data

${ }^{\mathrm{c}}$ Wilcoxon rank sum test 
${ }^{\mathrm{d}}$ Kruskal-Wallis test

${ }^{\mathrm{e}}$ Good Death Inventory score 


\title{
A survey for End-of-Life discussions with health care providers in the End-of-Life Phase of patients with a high-grade glioma
}

\author{
Questionnaire for relatives
}

\section{Instructions}

1. This booklet is the questionnaire for the "Survey of bereaved families for the clinical practice of End-of-Life discussions and quality of life at the End-of-Life phase of high-grade glioma patients".

2. This questionnaire should be completed by bereaved family members who are over the age of 20 years.

3. Responses should be filled in directly in the options and open-ended sections of this questionnaire.

4. Please read the instructions to the questionnaire, such as "single answer," "multiple answers," "please fill in certain number," etc., and circle the appropriate number or write the number directly on the questionnaire.

5. The questionnaire should take approximately 20 minutes to complete. We apologize for interrupting your busy schedule and thank you for your cooperation.

6. If you encounter any unfamiliar words or questions in the questionnaire, please do not hesitate to contact us using the contact information.

\section{The survey begins on the next page.}

We thank you in advance. 
I. Question regarding you (the bereaved family members).

For each of the questions below, (1) to (5), please tick the box or fill in the number before the parentheses.

(1) What is your sex? (Single answer)

$\square$ Male

$\square$ Female

(2) What is your age? (Please fill in a number)

( ) years old

(3) Which institution did you last graduate from? (Single answer)

$\square \quad$ Junior high school

$\square$ High school

$\square$ Vocational school

$\square$ Junior college

$\square$ University

$\square$ Graduate school

$\square \operatorname{Other}(\quad)$

(4) What is your relationship to the patient? (Single answer)
$\square$ Father
$\square$ Mother
$\square$ Brother/Sister
$\square$ Spouse
$\square$ Child
$\square$ Son-in-law/Daughter-in-law
$\square$ Grandson
$\square$ Uncle/Aunt
$\square$ Cousins
$\square$ Other 
(5) What was the extent of your involvement in the decision-making process regarding treatment and care? (Single answer)

$\square$ Complete involvement

$\square$ Partial involvement (e.g., when consulted by the patient or other family members)

$\square$ No involvement

\section{Questions regarding the deceased.}

For each of the questions below (6) to (12), please tick the box or fill in the number between the parentheses.

(6) What was the patient's age at the time of death? (Please fill in a number)

( ) years old

(7) Which institution did the patient last graduate from? (Single answer)

$\square$ Junior high school

$\square$ High school

$\square \quad$ Vocational school

$\square$ Junior college

$\square$ University

$\square$ Graduate school

$\square$ Other ( )

(8) What was the marital status of the patient? (Single answer)

$\square$ Single

$\square$ Living with partner

$\square$ Married

$\square$ Divorced

$\square$ Widow/widower

(9) What religion did the patient follow? (Single answer)

$\square$ Yes

$\square$ No

(10) What was the date of the patient's death?

Date: 
(11) Where was the patients' preferred place of death? (Single answer)

$\square$ Home

$\square$ Hospice and Palliative Care Unit

$\square$ Hospital

$\square$ Nursing home

$\square$ No hope

$\square$ Unknown

(12) Did the patient express their preferences for treatment and care in the case of a condition for which he or she would not be able to make medical decisions in advance to the families (e.g., loss of consciousness or coma)? (Single answer)

$\square$ Yes

$\square$ No

III. Questions regarding the End-of-Life discussions with the health care provider concerning the medical care and treatment that the patient would receive in the End-of-Life phase.

(13) During the patient's entire illness trajectory, did you and the patient participate in at least one discussion with a health care provider at the Kyoto University Hospital regarding treatment and care the patient would receive during the End-of-Life phase? If you have had more than one discussion, please select the option that best describes the type of participation. (Single answer)

Only the patients themselves $\rightarrow$ go to question (15)

Patient and family $\rightarrow$ go to question (15)

$\square$ Only family members $\rightarrow$ go to question (14)

$\square$ Never had a discussion $\rightarrow$ go to question (20) 
(14) For those who selected " Only family members " for question (13)

Please provide reasons as to why only your family participated in the discussion. (Single answer)

The family members, including you, were uncomfortable with knowing the details of the patient's medical condition

$\square$ The patient's consciousness and judgment were diminished or debilitated, and the patient himself or herself was not aware enough to participate in the discussion.

$\square$ Other (

The following questions (15) to (19) concern your experience with the End-of-Life discussions at Kyoto University Hospital. If you had more than one discussion during the same phase, please answer for the first discussion during that phase.

(15) The following questions (a) to (h) are intended for phase A (from diagnosis to end of initial treatment including surgery and chemoradiation)

(a) Did you participate in End-of-Life discussions? (Single answer)

$\square$ Yes

$\square$ No $\rightarrow$ go to question (16)

(b) Did the patient participate? (Single answer)

$\square$ Yes

No

(c) Was the patient's consciousness and decision-making capacity maintained at the time of End-of-Life discussion or not, compared to when they were in good health? (Single answer)

Maintained as well as when healthy

$\square$ Diminished or lost 
(d) Which health care providers participated in the discussion? (multiple answers)

Neurosurgeon

Nurse in the neurosurgery department

Nurse in the community healthcare coordination unit

Outpatient nurse

Physician in the palliative care team

$\square$ Nurse in the palliative care team

Radiologist

Medical social worker

Others

(e) Which topics were discussed with the health care providers? (multiple answers)

The patient's goals and priorities in life (e.g., what the patient valued in his/her daily life, what the patient wanted to do or achieve for the remainder of their life)

$\square$ Treatment goals and choices (e.g., withdrawal of anticancer therapy, use of palliative care)

Life-prolonging treatment (e.g., artificial respiration, cardiopulmonary resuscitation, artificial nutrition via gastric tube, gastric fistula, or vein)

Use of palliative care services for End-of-Life phase

$\square$ Preferred place of receiving End-of-Life treatment and care

$\square$ Preferred place of death

(f) Was the timing of the End-of-Life discussions appropriate? (Single answer)

Too early

Appropriate

Little bit late

Too late 
(16) The following questions (a) to (h) are intended for phase B (during maintenance adjuvant chemotherapy)

(a) Did you participate in the End-of-Life discussions? (Single answer)

$\square$ Yes

No $\rightarrow$ go to question (17)

(b) Did the patient participate? (Single answer)

Yes

No

(c) Was the patient's consciousness and decision-making capacity maintained at the time of the End-of-Life discussion or not, compared to when they were in good health? (Single answer)

$\square$ Maintained as well as when healthy

$\square$ Diminished or lost

(d) Which health care providers participated in the discussion? (multiple answers)

$\square$ Neurosurgeon

Nurse in the neurosurgery department

Nurse in the community healthcare coordination unit

Outpatient nurse

Physician in the palliative care team

Nurse in the palliative care team

$\square$ Radiologist

$\square$ Medical social worker

$\square$ Others 
(e) Which topics did you discuss with health care providers? (multiple answers)

$\square$ The patient's goals and priorities in life (e.g., what the patient valued in his/her daily life, what the patient wanted to do or achieve for the remainder of their life)

Treatment goals and choices (e.g., withdrawal of anticancer therapy, use of palliative care)

$\square$ Life-prolonging treatment (e.g., artificial respiration, cardiopulmonary resuscitation, artificial nutrition via gastric tube, gastric fistula, or vein)

Use of palliative care services for the End-of-Life phase

$\square$ Preferred place of receiving End-of-Life treatment and care

$\square$ Preferred place of death

(f) Was the timing of the End-of-Life discussion appropriate? (Single answer)

$\square$ Too early

$\square$ Appropriate

$\square$ Little bit late

Too late

(17) The following questions (a) to (h) are intended for phase $\mathrm{C} 1$ (recurrence and new treatment, including second and third surgeries, chemotherapy, and radiation therapy)

(a) Did you participate in the End-of-Life discussions? (Single answer)

$\square$ Yes

$\square$ No $\rightarrow$ go to question (18)

(b) Did the patient participate? (Single answer)

$\square$ Yes

$\square$ No

(c) Was the patient's consciousness and decision-making capacity maintained at the time of the End-of-Life discussions or not, compared to when they were in good health? (Single answer)

Maintained as well as when healthy

Diminished or lost 
(d) Which health care providers participated in the discussion? (multiple answers)

Neurosurgeon

Nurse in the neurosurgery department

Nurse in the community healthcare coordination unit

Outpatient nurse

$\square$ Physician in the palliative care team

$\square$ Nurse in the palliative care team

Radiologist

Medical social worker

Others

(e) Which topics did you discuss with health care providers? (multiple answers)

$\square$ The patient's goals and priorities in life (e.g., what the patient valued in his/her daily life, what the patient wanted to do or achieve for the remainder of their life)

Treatment goals and choices (e.g., withdrawal of anticancer therapy, use of palliative care)

$\square$ Life-prolonging treatment (e.g., artificial respiration, cardiopulmonary resuscitation, artificial nutrition via gastric tube, gastric fistula, or vein)

Use of palliative care services for the End-of-Life phase

$\square$ Preferred place of receiving End-of-Life treatment and care

$\square$ Preferred place of death

(f) Was the timing of the End-of-Life discussion appropriate? (Single answer)

Too early

Appropriate

Little bit late

Too late 
(18) The following questions (a) to (h) are intended for phase $\mathrm{C} 2$ (the timing of final tumor-directed treatment)

(a) Did you participate in the End-of-Life discussions? (Single answer)

$\square$ Yes

$\square$ No $\rightarrow$ go to question (19)

(b) Did the patient participate? (Single answer)

$\square$ Yes

$\square$ No

(c) Was the patient's consciousness and decision-making capacity maintained at the time of the End-of-Life discussions or not, compared to when they were in good health? (Single answer)

$\square$ Maintained as well as when healthy

$\square$ Diminished or lost

(d) Which health care providers participated in the discussion? (multiple answers)

Neurosurgeon

Nurse in the neurosurgery department

Nurse in the community healthcare coordination unit

Outpatient nurse

Physician in the palliative care team

Nurse in the palliative care team

Radiologist

$\square$ Medical social worker

Others 
(e) Which topics did you discuss with health care providers? (multiple answers)

$\square$ Patient's goals and priorities in life (e.g., what the patient valued in his/her daily life, what the patient wanted to do or achieve for the remainder of their life)

Treatment goals and choices (e.g., withdrawal of anticancer therapy, use of palliative care)

$\square$ Life-prolonging treatment (e.g., artificial respiration, cardiopulmonary resuscitation, artificial nutrition via gastric tube, gastric fistula, or vein)

Use of palliative care services for the End-of-Life phase

$\square$ Preferred place of receiving End-of-Life treatment and care

$\square$ Preferred place of death

(f) Was the timing of the End-of-Life discussion appropriate? (Single answer)

Too early

Appropriate

Little bit late

Too late

(19) Ask about the following (a) to (h) for phase D (The timing of hospice palliative care and/or life-prolonging treatment during dying phase)

(a) Did you participate in the End-of-Life discussions? (Single answer)

$\square$ Yes

$\square$ No $\rightarrow$ go to question (21)

(b) Did the patient participate? (Single answer)

$\square$ Yes

$\square$ No

(c) Was the patient's consciousness and decision-making capacity maintained at the time of the End-of-Life discussions or not, compared to when they were in good health? (Single answer)

Maintained as well as when healthy

Diminished or lost 
(d) Which health care providers participated in the discussion? (multiple answers)

Neurosurgeon

Nurse in the neurosurgery department

Nurse in the community healthcare coordination unit

Outpatient nurse

$\square$ Physician in the palliative care team

$\square$ Nurse in the palliative care team

Radiologist

Medical social worker

Others

(e) Which topics did you discuss with health care providers? (multiple answers)

$\square$ Patient's goals and priorities in life (e.g., what the patient valued in his/her daily life, what the patient wanted to do or achieve for the remainder of their life)

Treatment goals and choices (e.g., withdrawal of anticancer therapy, use of palliative care)

$\square$ Life-prolonging treatment (e.g., artificial respiration, cardiopulmonary resuscitation, artificial nutrition via gastric tube, gastric fistula, or vein)

Use of palliative care services for the End-of-Life phase

$\square$ Preferred place of receiving End-of-Life treatment and care

$\square$ Preferred place of death

(f) Was the timing of the End-of-Life discussion appropriate? (Single answer)

Too early

Appropriate

Little bit late

Too late 
(20) For those who selected "Never had a discussion" for question (14)

Why would the patient and family members not have had an End-of-Life discussion at Kyoto University Hospital? (Single answer)

The patient's condition deteriorated rapidly and there was no time to discuss it

$\square$ All decisions about treatment and care were left to physicians and other health care providers

Had discussions in other hospitals, clinics, and other health care providers

$\square$ Other 
IV. The following will address the medical treatment and care the patient received during hospitalization or at home during phase $D$ (the timing of hospice palliative care and/or life-prolonging treatment during dying phase).

How do you think the patient was feeling during the hospitalization or at home?

Please circle the most appropriate number. (Each single answer)

\begin{tabular}{|c|c|c|c|c|c|c|c|c|}
\hline & 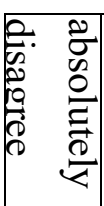 & 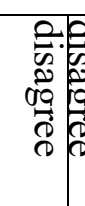 & 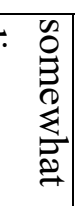 & $\begin{array}{l}\Im_{0}^{\circ} \\
0 \\
0 \\
0\end{array}$ & 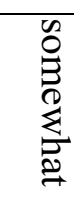 & 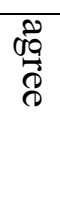 & $\frac{10}{80}$ & 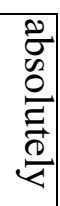 \\
\hline 1. Being free from physical distress & 1 & 2 & 3 & 4 & 5 & 6 & & 7 \\
\hline 2. Being able to stay at one's favorite place & 1 & 2 & 3 & 4 & 5 & 6 & & 7 \\
\hline 3. Having some pleasure in daily life & 1 & 2 & 3 & 4 & 5 & 6 & & 7 \\
\hline 4. Trusting physician & 1 & 2 & 3 & 4 & 5 & 6 & & 7 \\
\hline 5. Not being a burden to others & 1 & 2 & 3 & 4 & 5 & 6 & & 7 \\
\hline 6. Spending enough time with one's family & 1 & 2 & 3 & 4 & 5 & 6 & & 7 \\
\hline 7. Being independent in daily activities & 1 & 2 & 3 & 4 & 5 & 6 & & 7 \\
\hline 8. Living in calm circumstances & 1 & 2 & 3 & 4 & 5 & 6 & & 7 \\
\hline 9. Being valued as a person & 1 & 2 & 3 & 4 & 5 & 6 & & 7 \\
\hline 10. Feeling that one's life was completed & 1 & 2 & 3 & 4 & 5 & 6 & & 7 \\
\hline 11. Receiving enough treatment & 1 & 2 & 3 & 4 & 5 & 6 & & 7 \\
\hline 12. Dying a natural death & 1 & 2 & 3 & 4 & 5 & 6 & & 7 \\
\hline 13. Saying what one wants to tell dear people & 1 & 2 & 3 & 4 & 5 & 6 & & 7 \\
\hline $\begin{array}{l}\text { 14. Knowing what to expect about one's condition in } \\
\text { the future }\end{array}$ & 1 & 2 & 3 & 4 & 5 & 6 & & 7 \\
\hline 15. Dying without awareness that one is dying & 1 & 2 & 3 & 4 & 5 & 6 & & 7 \\
\hline $\begin{array}{l}\text { 16. Not exposing one's physical and mental weakness } \\
\text { to family }\end{array}$ & 1 & 2 & 3 & 4 & 5 & 6 & & 7 \\
\hline
\end{tabular}




\begin{tabular}{|l|l|l|l|l|l|l|l|}
\hline 17. Feeling that one's life is worth living & 1 & 2 & 3 & 4 & 5 & 6 & 7 \\
\hline 18. Supported by religion & 1 & 2 & 3 & 4 & 5 & 6 & 7 \\
\hline
\end{tabular}


V. Please provide us with your assessment of the medical treatment and care you received at the place where the patient died, within a month before patient's death. Please circle the number that best describes the question.

If not applicable (e.g., the patient had no pain at all), please select "Not applicable". (Each single answer)

\begin{tabular}{|c|c|c|c|c|c|c|c|}
\hline & 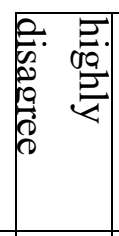 & 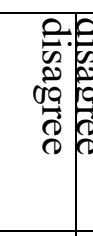 & 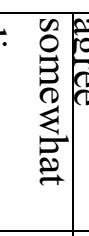 & 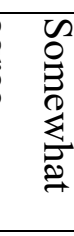 & 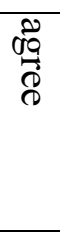 & 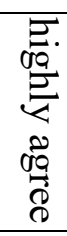 & 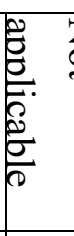 \\
\hline $\begin{array}{l}\text { 1. Physicians endeavored to relieve physical } \\
\text { discomfort of the patient }\end{array}$ & 1 & 2 & 3 & 4 & 5 & 6 & 7 \\
\hline $\begin{array}{l}\text { 2. Nurses endeavored to relieve physical discomfort } \\
\text { of the patient }\end{array}$ & $\mathrm{t}$ & 2 & 3 & 4 & 5 & 6 & 7 \\
\hline $\begin{array}{l}\text { 3. Physicians, nurses and staff endeavored to relieve } \\
\text { patients' concerns and worries. }\end{array}$ & $\mathrm{e}$ & 2 & 3 & 4 & 5 & 6 & 7 \\
\hline $\begin{array}{l}\text { 4. Physicians gave sufficient explanation to the } \\
\text { patient about condition and the medical treatment }\end{array}$ & 1 & 2 & 3 & 4 & 5 & 6 & 7 \\
\hline $\begin{array}{l}\text { 5. Physician gave sufficient explanation to the family } \\
\text { about condition and the medical treatment }\end{array}$ & 1 & 2 & 3 & 4 & 5 & 6 & 7 \\
\hline 6. Hospital or room was convenient and comfortable & 1 & 2 & 3 & 4 & 5 & 6 & 7 \\
\hline 7. Consideration was given to the health of family & 1 & 2 & 3 & 4 & 5 & 6 & 7 \\
\hline 8. The total cost is reasonable & 1 & 2 & 3 & 4 & 5 & 6 & 7 \\
\hline $\begin{array}{l}\text { 9. Admission (use) is possible when necessary } \\
\text { without waiting }\end{array}$ & 1 & 2 & 3 & 4 & 5 & 6 & 7 \\
\hline $\begin{array}{l}\text { 10. There is good cooperation among staff members } \\
\text { such as physicians and nurses }\end{array}$ & 1 & 2 & 3 & 4 & 5 & 6 & 7 \\
\hline
\end{tabular}

Thank you for completing this questionnaire. 